\title{
OS FATORES ESTRESSANTES EM ENFERMEIROS DA ESTRATÉGIA DE SAÚDE DA FAMÍLIA
}

DOI: $10.22289 / 2446-922 X . V 5 N 1 A 6$

\author{
Suellen Xavier Garcia ${ }^{1}$ \\ Luiza Araújo Amâncio Sousa
}

\section{RESUMO}

Este trabalho tem como objetivo levantar os principais fatores estressantes que acometem o enfermeiro atuante na Estratégia de Saúde da Família tais como: a falta de recurso, a desvalorização salarial, a carga horária excessiva, a falta de trabalho em equipe, entre outros. Ademais o trabalho procurou também conceituar o estresse e discorrer sobre o impacto que está causa nos profissionais, a fim de, apontar medidas de melhorias para que esse profissional possa lidar com tais situações de ansiedade, buscando o prazer e a satisfação. Os resultados apontam medidas que podem ser realizadas através de terapias e relaxamentos que possam favorecer 0 descanso da mente, melhorar o diálogo perante a equipe de saúde e aumentar a produtividade, favorecendo, assim, para um ambiente de trabalho estável e harmonioso, fazendo com que o enfermeiro possa desenvolver com qualidade suas atribuições diárias e melhorar sua qualidade de vida.

Palavras-chave: Estresse; Saúde da família; Enfermeiro. Fatores de risco.

\section{ABSTRACT}

The goal of this article is to survey the main stressing factors that affect the nurse working in family health strategy such as lack of resources, wage devaluation, excessive workload, lack of teamwork, among others. Furthermore, the article also sought to conceptualize stress and discuss the impact that it causes on professionals, in order to point improvement measures that can be performed by the professional so that they can deal with anxiety situations, seeking pleasure and satisfaction. These measures can be carried out through therapies, relaxations that can favor the ease of the mind, improve the dialogue with the health team, increase productivity, thus favoring a stable and harmonious workplace, enabling nurses to develop with quality their daily labor and improve their life quality.

Keywords: Stress; Family Health; Nurse; Risk factors.

\footnotetext{
${ }^{1}$ Endereço eletrônico de contato: suellen.xaviergarcia@yahoo.com

Recebido em 30/08/2018. Aprovado pelo conselho editorial para publicação em 20/10/2018.
}

Rev. Psicol Saúde e Debate. Jul., 2019:5(1):60-69. 


\section{INTRODUÇÃO}

O enfermeiro na Estratégia de Saúde da Família (ESF) é responsável por verificar e colaborar com o trabalho dos Agentes Comunitários de Saúde (ACS) e também dos demais profissionais de enfermagem, sendo estes de nível técnico. Além disso, ele é o responsável no que diz respeito à aplicação de cuidados aos que necessitam como: crianças, adolescentes e idosos. Atuante dentro da ESF, o enfermeiro se torna mediador de várias funções. Dentre estas, se encontram o planejamento de ações de promoção à saúde e reabilitação. São profissionais que tomam decisões pautadas no diagnostico local, com auxílio de sua equipe (Souza, et al., 2012).

O trabalho do enfermeiro é de suma importância para a construção das atividades e dos serviços prestados a comunidade. Estes atuam no planejamento e na execução de ações na assistência básica de vigilância epidemiológica e sanitária. Seu compromisso é de alta complexidade e envolvem tarefas como: desenvolver ações de capacitação aos Agentes Comunitários de Saúde (ACS) e técnicos de enfermagem; oportunizar os contatos com indivíduos sadios ou doentes, visando promover a saúde e abordar os aspectos de educação sanitária, viabilizando a qualidade de vida e contribuindo para que o meio ambiente se torne mais saudável. Ministério da Saúde [MS] (1997).

O enfermeiro atuante na função de coordenador da equipe assume diversos compromissos no seu dia a dia, o que pode acarretar em uma sobrecarga, gerando um ambiente de trabalho hostil, o que por sua vez, propicia um cansaço emocional, devido à alta quantidade de tarefas. Tais fatores podem desencadear um possível estresse, que pode estar relacionado ao desgaste, tornando-se uma preocupação ao profissional que não se encontra apto a suportar tais situações (Araújo \& Oliveira, 2009).

Segundo Stacciarini e Tróccoli (2001), o estresse causa perda ao desenvolvimento global, que pode ser causado por vários motivos, como o grande nível de pressão do trabalho, podendo ser considerado uma dificuldade em resolver pequenos problemas que ocorrem dentro da Estratégia da Saúde da Família. Acredita-se que o profissional de enfermagem, atuante na ESF, esteja diariamente exposto a diversos fatores que contribuem diretamente para ocorrência de estresse.

Portanto, este trabalho tem como finalidade levantar os fatores estressantes do profissional de enfermagem, atuante na Estratégia da Saúde da Família, conceituar estresse e o impacto no profissional de enfermagem, levantar principais fatores estressantes que acometem este profissional da ESF, além de averiguar medidas de melhorias para a qualidade de trabalho do mesmo.

Rev. Psicol Saúde e Debate. Jul., 2019:5(1):60-69. 


\section{MÉTODO}

A pesquisa trata-se de um estudo de revisão narrativa conceitual. Para a realização da revisão, foram abordadas algumas categorias previamente selecionadas, sendo estas: estresse, saúde da família, enfermeiro e fatores de risco. Para o levantamento dos estudos, foram selecionadas pesquisas que abordem o tema proposto em artigos científicos nas bases da BVS, Bireme, Scielo, MeLine e publicações em revistas científicas entre outras, sendo artigos que variam entre 1997 a 2017, com ênfase nos que se encontram entre os anos 2010 a 2017.

A análise dos estudos seguiu à lógica de apresentar os aspectos, as quais contemplem o estresse na Estratégia de Saúde da Família, enfermeiro e fatores de riscos. A discussão do tema apresentado.

\section{DESENVOLVIMENTO}

Segundo Bozza e Fontanela (2008), estresse deriva de uma palavra inglesa com origem no vocábulo latino stringere que significa: angústia, aperto, opressão, desconforto e adversidade.

Stacciarini e Tróccoli (2001) relatam que o "estresse" se trata de um problema negativo de natureza perceptiva, e que ele resulta da incapacidade de lidar com as causas de pressão no dia a dia de laboro. Isso ocorre devido a uma carga de trabalho que o próprio profissional acumula para si, a qual, este acredita ser a forma correta de desenvolver suas próprias tarefas laborais ou até mesmo devido à falta de recursos, o que mina a sua motivação e reduz o seu estímulo de realizar um trabalho eficaz.

As situações de stress podem se tornar evidentes através de alguns distúrbios que se manifestam no corpo humano ou até mesmo perda de capacidade de realização do cumprimento de tarefas, devido à dificuldade que o profissional tem de se adaptar, concordar ou dominar, as demandas de trabalho. A partir daí, então, pode-se gerar uma grande pressão psicológica em seu ambiente de ocupação (Ferreira et al., 2017).

O estresse pode desencadear alguns fatores de insatisfação no profissional de saúde, que atua dentro da estratégia da família, impedindo o seu pleno desenvolvimento profissional ou de sua equipe de trabalho. A falta de motivação pode contribuir para o aparecimento de sentimentos como o medo e a tensão, e impedir que seu trabalho seja realizado com êxito (Barstow, 1980 citado por Stacciorini \& Tróccoli, 2001).

É possível que o acúmulo de tarefas possa comprometer o desempenho e atuação do enfermeiro devido ao grande nível de responsabilidade que é oferecido a este, podendo afetar o seu pleno exercício de trabalho, provocando uma sobrecarga. Por isso, pode ser observado uma

Rev. Psicol Saúde e Debate. Jul., 2019:5(1):60-69. 
má condição no exercício de seu cargo, com uma grande demanda de metas a serem cumpridas, além do prazo curto para realização de atividades e a desvalorização profissional (Ferreira et al., 2017).

Portanto, cabe ao enfermeiro estar atendo quanto à organização de suas funções, buscando os melhores recursos para que possa proporcionar o monitoramento dos mecanismos de trabalho, adotando uma boa conduta ética, que o permita conduzir seus encargos de forma correta e sensata, procurando oferecer sempre uma boa qualidade de vida para a comunidade.

Contudo, o seu papel dentro da Estratégia de Saúde da Família é de gerenciar a assistência prestada, promover e participar de grupos de educação em saúde, efetuar consultas de enfermagem, solicitar pedidos de exames, realizar o encaminhamento para consulta médica, atuar em exames citopatológicos, planejar, administrar e investigar o trabalho dos ACS e os técnicos de enfermagem (Souza et al., 2012).

A enfermagem, no seu trabalho diário, destacando-se principalmente a figura do enfermeiro, fica, por vezes, exposta aos fatores de risco decorrentes de episódios estressantes que podem ocorrer durante sua carga horária semanal, carga esta que não possibilita um tempo suficiente para realização de atividades, que devem ser efetivadas em curtos prazos (Ferreira et al., 2017).

Além disso, o enfermeiro nem sempre possui boas condições de trabalho que o permita realizar essas funções de forma satisfatória, o que pode lesar os serviços oferecidos a comunidade, devido aos problemas que estão diariamente acontecendo na Estratégia de Saúde da Família (Trindade et al., 2010).

Existem outros fatores que podem ser observados, e que, possivelmente levam à insatisfação profissional, como a inadequação do ambiente laboral, a falta de materiais para realização de procedimentos e a ausência de equipamentos para a proteção contra riscos de acidentes. Muitas vezes, a ausência destes recursos dificulta a realização de tarefas que são consideradas essenciais para os programas que são oferecidos (Trindade et al., 2010).

A Estratégia de Saúde da Família atua em um cenário em que há um conjunto de ações em que se faz necessária a presença de uma equipe multiprofissional, que esteja capacitada para oferecer um atendimento público para a população de um determinado território. A família é o objeto principal da atenção e todas as ações são realizadas de acordo com a realidade local. A ESF é composta por enfermeiros, médicos, pelos Agentes Comunitários de Saúde (ACS), serviços odontológicos e os técnicos de enfermagem (MS, 1997).

Sua finalidade é realizar ações de proteção e promoção a saúde, diagnósticos e tratamentos na reparação e na assistência a mesma, com o objetivo de gerar uma atenção integral, que promova o encontro na condição de saúde no domínio individual e comunitário (Jesus et al., 2015).

Rev. Psicol Saúde e Debate. Jul., 2019:5(1):60-69. 
E necessário uma equipe que esteja disposta a oferecer um bom serviço à comunidade, na qual o trabalho em conjunto se faz necessário para que se obtenham bons resultados no âmbito da saúde, principalmente em setores prioritários, nos quais as demandas aumentam frequentemente. Normalmente, as opções de trabalho não são condizentes com a realidade (Cardoso et al., 2016).

Camelo e Angerami (2004) afirmam que o trabalho em equipe deve promover condutas coerentes, para que ocorra o crescimento pessoal e profissional. Portanto, o enfermeiro deve estar preparado para lidar com as diversidades que surgirão no decorrer de sua jornada.

E de extrema importância que ele consiga lidar com as suas obrigações, envolvendo-se junto a sua equipe, sendo esta, parte de um seguimento, o qual tenha a soma de apoio geral da população. Por isso, faz-se necessário oferecer ótimas condições, para que possam favorecer o desenvolvimento social destas famílias (Pires et al., 2016).

Segundo Soares et al. (2017), é importante ressaltar que devido às atividades que são oferecidas no decorrer de seu trabalho, o enfermeiro nem sempre exerce sua profissão com plenitude, devido aos inúmeros fatores que podem acarretar o estresse, sendo estes: a falta de recurso, a infraestrutura inadequada, a pouca quantidade de profissionais e a ausência de compromisso de funcionários.

Lentine et al. (2003) aborda pesquisa feita em 51 UBS diferentes, realizada no município de Londrina que mostra a realidade deste profissional, totalizando em 102 enfermeiros. Obtevese dados onde aponta que $42 \%$ são insatisfeitos com a renda salarial mensal, $85 \%$ relata carga horaria excessiva, $62 \%$ consideram seu ambiente de trabalho estressante, e $19 \%$ enfatizou tendo como maior causa de estresse a grande demanda.

Conforme dito por Soares et al. (2017), o estresse pode causar reações do organismo nas formas física e psíquica, capazes de afetar o equilíbrio emocional, apresentando sintomas como: perda de concentração mental, fadiga facial, fraqueza e mal-estar. É possível também perceber o descontrole e a agressividade, que podem gerar depressão, angústia, tremores, calafrios, tonteiras e até mesmo dores no estômago.

Acredita-se que o estresse pode acontecer com grande facilidade no dia-dia do profissional de enfermagem, uma vez que vão surgindo problemas no decorrer de suas atividades e, na maioria das vezes, estes não são fáceis de serem solucionados. Um dos fatores que podem contribuir para este desconforto, gerado pelo estresse, é a falta de apoio da gestão e da própria equipe de saúde.

Neste sentido, é notável que, na maioria das vezes, o profissional de enfermagem dentro da Estratégia de Saúde da Família, não possui um bom reconhecimento, e isto faz com que a insatisfação de seu trabalho ocorra com percentual significativo em seu dia a dia, possibilitando 
a permanência de estímulos estressores, e fazendo com que ocorra o esgotamento ou exaustão nas atividades laborais que são confiadas a sua responsabilidade (Ribeiro et al., 2003).

É importante ressaltar que, quando existe grande sobrecarga no ambiente de trabalho, o enfermeiro acaba se tornando uma vítima, com uma predisposição a sofrer, ou acarretar tais situações decorrentes de ansiedade e frustração, levando ao adoecimento físico e mental, o que acaba impedindo que seu trabalho seja feito com satisfação. (Cardoso et al., 2016).

A sobrecarga de trabalho deste profissional pode ser refletida através da falta de desempenho para lidar com situações perante a assistência prestada às famílias e aos funcionários. Por isso, o enfermeiro deve buscar formas de enfrentamento, visando obter mecanismos de defesa e adequação ao estresse. (Souza et al., 2012).

Conforme dados estatísticos mostrados anteriormente pode se entender que quando existem grandes responsabilidades e múltiplas tarefas, levando a sobrecarga e o esgotamento, o enfermeiro deve buscar medidas de melhorias para que consiga lidar com as circunstâncias causadoras de estresse, e desenvolver seu trabalho com satisfação, não permitindo que estas situações atrapalhem a sua vida particular e profissional (Lentine et al.,2003).

Os dados apresentados demonstram que o estresse é um dos principais fatores que impede que o profissional de enfermagem realize um bom trabalho em seu cotidiano, e que alguns dos motivos que causam tal estresse são: o grande acúmulo de demandas a serem atendidas, a falta de recurso e a sobrecarga de atividades. E estes entraves podem afetar a vida pessoal do profissional (Fontana \& Siqueira, 2009).

Contudo, é importante ressaltar que o enfermeiro que atua dentro da Estratégia de Saúde da Família, deve estar sempre atento as funções que lhes são oferecidas, buscando manter a organização do seu trabalho para que, no decorrer de suas tarefas não haja transtornos, diminuindo assim, a ocorrência de estresse.

É notável que a ocupação do enfermeiro em alguns cargos faz com que este perca um pouco de sua autonomia, dificultando o alcance de suas metas. O seu exercício, muitas vezes, é capaz de se tornar a razão do seu sofrimento, uma vez que se perde o controle da ação. Devese sempre buscar o domínio emocional, entendendo o real motivo de estar ali, a fim de, desfrutar de momentos de prazer em seu ambiente de trabalho. (Trindade et al., 2010)

Pode ser necessário buscar medidas de ajuda terapêutica, que possam proporcionar a este profissional o autocontrole, como forma de enfrentamento do estresse, fazendo uso de algumas atividades que possa favorecer o relaxamento, através de músicas e massagens, por exemplo. Assim, o enfermeiro poderá alcançar bons resultados na diminuição dos níveis de estresse. (Ribeiro et al., 2012)

Portanto, o enfermeiro deve primeiramente entender a situação que está vivenciando no momento, compreendendo por que o estresse pode prejudicar tanto sua profissão, uma vez que, 
este, pode fazê-lo perder o interesse e a satisfação de realizar seu compromisso, por causa das dificuldades que vão surgindo, podendo provocar, então, o adoecimento, devido ao grande desgaste emocional (Fontana \& Siqueira, 2009).

Segundo Oliveira et al. (2017), 19\% dos enfermeiros não possui relações interpessoais entre si, por isso e importante que o mesmo não se prive de relatar suas aflições, incômodos ou insatisfação perante aos acontecimentos que vão se manifestando no decorrer de suas atividades, compartilhando com seus colegas de trabalho o que no momento pode estar se tornando um desconforto profissional.

É importante que o profissional compreenda que, para existir o reconhecimento e a valorização do seu cargo, primeiramente, este deve possuir satisfação em realizar suas atividades no trabalho, desenvolvendo aquilo que for necessário e se permitindo aceitar que nem sempre tudo poderá dar certo. Buscando entender o principal motivo que o leva a gerenciar seu papel como enfermeiro que atua dentro de uma estratégia (Daubermann \& Tonete, 2012).

Além disso, é necessário ficar atento quanto ao convívio de sua equipe, procurando sempre o diálogo e o planejamento, para levar medidas de melhoria para a comunidade, como a capacitação dos funcionários, através de educação continuada, o que permite a interação entre estes profissionais, tornando o local de trabalho agradável (Kessler \& Krug, 2012).

O enfermeiro deve funcionar como peça fundamental perante sua atuação, o que o torna capaz de desenvolver suas obrigações com sabedoria e discernimento, buscando sempre o reconhecimento dentro de sua equipe, tendo em vista a prática de se aprimorar para oferecer um bom trabalho a população, proporcionando melhorias no âmbito social (Araújo \& Oliveira, 2009).

Sendo assim, pode se considerar que, diante da grande responsabilidade que o enfermeiro assume dentro da estratégia de saúde, a exaustão pode se tornar um dos grandes problemas, que o impede de oferecer serviços com uma boa qualidade. Desta forma, é preciso que esse profissional busque artifícios que possam ajudá-lo a lutar contra os fatores resultantes de estresse.

\section{CONSIDERAÇÕES FINAIS}

O enfermeiro, na gestão de uma Estratégia de Saúde da Família, assume diversos compromissos diários dentro da sua atuação, liderando uma equipe que tem como foco principal a promoção da saúde de uma população e seus serviços oferecidos. São inúmeras funções que de fato se fazem presentes na sua vivência profissional, fazendo com que haja muito comprometimento e responsabilidade no seu ambiente de trabalho. 
Diante da grande responsabilidade que o enfermeiro assume dentro da estratégia de saúde, a exaustão pode se tornar um dos grandes problemas, que o impede de oferecer serviços com uma boa qualidade. Desta forma, é preciso que esse profissional busque artifícios que possam ajudá-lo a lutar contra os fatores resultantes de estresse.

De acordo com que foi discutido, esse profissional pode estar vulnerável a absorver ansiedade, devido ao grande nível de pressão diária, entre outros fatores que se fazem presentes em seu ambiente profissional. O estresse pode surgir facilmente quando o seu trabalho não se torna uma atividade que lhe traga benefícios e acabe gerando incômodo, que o faz perder o interesse em desenvolver suas tarefas.

Faz-se necessário, portanto, que o coordenador de equipe esteja preparado para lidar com todas as situações que poderão surgir e entender a importância de suas funções colaborativas diante da comunidade e de sua equipe de trabalho.

Várias medidas podem ser tomadas com a finalidade de aumentar a satisfação e o prazer deste profissional que está exposto a diversos fatores de estresse. É importante ressaltar também o autocuidado, para que ele esteja preparado e possa oferecer um melhor atendimento à população.

Este estudo foi elaborado, a fim de, levantar os principais fatores que levam o profissional de enfermagem a situações de estresse, os quais comprometem a atuação deste profissional, no que diz respeito às suas atividades laborais de forma adequada. Notou-se também que, os fatores que levam estes profissionais a sofrerem com o estresse são inúmeros e incluem a desvalorização salarial, a carga horária elevada, além de suas condições físicas e a falta de acompanhamento da equipe, tudo isso gera um grande desgaste físico e emocional, o que contribui para o dessabor das suas funções e facilita o encargo de problemas maiores em sua vida profissional.

Sendo assim, o enfermeiro, como líder e coordenador de sua equipe, deve ter um olhar crítico e mais apurado ante as situações desafiadoras, por mais que este profissional sofra com a autocobrança na execução com excelência das atividades realizadas diariamente. Levantouse, desta maneira, a importância de ter um olhar humanizado para cuidar de quem cuida, e de uma análise crítica e reflexiva dos fatores ambientais causadores de estresse, facilitando, assim, a implantação de mais medidas de melhorias no ambiente de trabalho.

\section{REFERÊNCIAS}

Araújo, M. D. F. S. D. \& Oliveira, F. M. C. D. (2009). A atuação do enfermeiro na equipe de Saúde da Família e a satisfação profissional. Revista Eletrônica de Ciências Sociais, 13, pp. 03-14. 
Bozza, M. S. S. \& Fontanela, G. A. (2008). Os fatores desencadeantes do estresse no enfermeiro que atua no setor de emergência. Nursing, 11(127), pp. 553-558. Recuperado em 22 de março, 2018, de <http://bases.bireme.br/cgibin/wxislind.exe/iah/online/? IsisScript=iah/iah.xis\&src=google\&base=BDENF\&lang=p\&next Action=Ink\&exprSearch=15639\&indexSearch=ID>

Camelo, S. H. H. \& Angerami, E. L. S. (2004). Sintomas de estresse nos trabalhadores atuantes em cinco núcleos de saúde da família. Revista Latino-Americana de Enfermagem, 12(1), pp. 14-21.

Cardoso, F. M., Lima, D. A., Leal, A. L. E., Mangueira, S. A. L., Carneiro, J. A. \& Costa, F. M. (2016). Risco de estresse no trabalho de enfermeiros da Estratégia Saúde da Família. Revista Norte Mineira de Enfermagem, 5(2), pp. 74-87.

Daubermann, D. C. \& Tonete, V. L. P. (2012). Qualidade de vida no trabalho do enfermeiro da Atenção Básica à Saúde. Acta Paulista de Enfermagem, 25(2), pp. 277-283.

Ferreira, J. S., Ribeiro, K. V., Caramuru, P. S., Hanzelmann, R. S., Velasco, A. R. \& Passo, J. P. (2017). Estresse e estratégias de enfrentamento em trabalhadores de enfermagem de uma unidade de saúde da família. Revista Online de Pesquisa Cuidado é Fundamental. 9(3), pp. 818-823.

Fontana, R. T. \& Siqueira, K. I. (2009). O trabalho do enfermeiro em saúde coletiva e o estresse: análise de uma realidade. Cogitare Enfermagem, 14(3), pp. 491-498.

Jesus, T. B. D., Flores, J. \& Santos, C. O. D. (2015). Riscos ocupacionais em enfermagem na estratégia de saúde da família - estudo bibliométrico. Enfermagem Contemporânea, 4(2), pp. 244-253.

Kessler, A. I. \& Krug, S. B. F. (2012). Do prazer ao sofrimento no trabalho da enfermagem: o discurso dos trabalhadores. Revista Gaúcha de Enfermagem, 33(1), pp. 49-55.

Lentine, E. C., Sonoda, T. K. \& Biazin, D. T. (2003). Estresse de profissionais da saúde das Unidades Básicas do Município de Londrina. Terra e Cultura, 19 (37), pp. 103-123.

Ministério da Saúde. (1997). Saúde da Família: uma estratégia para a reorientação do modelo assistencial.

Pires, D. E. P. D., Machado, R. R., Soratto, J., Schere, M. A., Gonçalves, A. S. R. \& Trindade, L. L.I. (2016). Cargas de trabalho da enfermagem na saúde da família: implicações no acesso universal. Revista Latino-Americana de Enfermagem, 24, pp. 1-9.

Ribeiro, R. P., Martins, J. T., Marziale, M. H. P. \& Robazzi, M. L. C. C. (2012). O adoecer pelo trabalho na enfermagem: uma revisão integrativa. Revista da Escola de Enfermagem da USP, 46(2), pp. 495-504.

Soares, L. M. P., Oliveira, V. C. \& Sousa, L. A. A. (2017, dezembro). Qualidade de vida dos profissionais atuantes no Centro Cirúrgico. Psicologia e Saúde em Debate, 3(2), pp. 159170.

Souza, D. F., Schimith, M. D. Segabinazi, A. D., Alves, C. N., Wilhelm, L. A., Silva, S. C., Stumm, K. E. \& Ressel, L. B. (2012). O papel do enfermeiro em um a estratégia de Saúde da Família: um relato de experiência. Recuperado em 26 abril, 2018, de $<$ http://docplayer.com.br/14387234-O-papel-do-enfermeiro-em-uma-estrtegia-de-saude-dafamilia-um-relato-de-experiencia-1.html>.

Stacciarini, J. M. R. \& Trócooli, B. T. (2001). O estresse na atividade ocupacional do enfermeiro. Revista Latino-Americana de Enfermagem, 9(2), pp. 17-25. 
Trindade, L. D. L., Lautert, L. Beck, C. L. C., Amestoy, S. C. \& Pires, D. E. P. (2010). Estresse e síndrome de burnout entre trabalhadores da Saúde da Família. Acta Paulista de Enfermagem, 23(5), pp. 684-689 